\title{
Number of Lines Unread
}

National Cancer Institute

\section{Source}

National Cancer Institute. Number of Lines Unread. NCI Thesaurus. Code C142355.

The number of lines not able to be read by the subject during an eye chart assessment. 